\title{
STRESS RELAXATION OF SILICON NITRIDE AT ELEVATED TEMPERATURES ${ }^{*}$
}

A. A. Wereszczak, M. K. Ferber, T. P. Kirkland, and E. Lara-Curzio High Temperature Materials Laboratory

Oak Ridge National Laboratory

Oak Ridge, TN 37831-6069

V. Parthasarathy

Solar Turbines, Inc.

San Diego, CA 92138

T. T. Gribb

Materials Science \& Engineering Dept.

University of Wisconsin

Madison, WI 53706

\begin{abstract}
The stress relaxation behavior of SN88, SN253, and NCX-5102 silicon nitride materials were experimentally determined in tension at $1300^{\circ} \mathrm{C}$ using buttonhead specimens. Specimens were held at constant strain after being loaded at $10 \mathrm{MPa} / \mathrm{s}$ to an initial stress of $276 \mathrm{MPa}(40 \mathrm{ksi})$ or $414 \mathrm{MPa}$ $(60 \mathrm{ksi})$. The subsequent decay in tensile stress was measured as a function of time. A non-negative least squares algorithm used in conjunction with a generalized Maxwell model proved to be an efficient means to define characteristic relaxation modulus spectra and stress relaxation behavior. In the last part of this study, the utility of using short-term stress relaxation testing to predict long-term creep performance was examined.
\end{abstract}

\section{INTRODUCTION}

The characterization and understanding of creep-induced stress relaxation behavior of candidate silicon nitride materials at elevated temperatures are required for successful high temperature service. Designers of stationary gas turbine engines and their components must acknowledge that the tightness of mechanically fastened joints at high temperatures lessens as stress relaxes in the materials comprising them. In addition, it is advantageous for designers to know how the component material will react to a stress concentrator at elevated temperatures; namely, will the material relax fast enough at temperature to avoid the initiation of damage associated with the stress concentrator and its associated higher stress intensity?

* Research sponsored by the U. S. Department of Energy, Assistant Secretary for Energy Efficiency and Renewable Energy, Office of Industrial Technologies, Industrial Energy Efficiency Division and Advanced Turbine Systems Program, under contract DE-AC05-84OR21400 with by Martin Marietta Energy Systems, Inc.

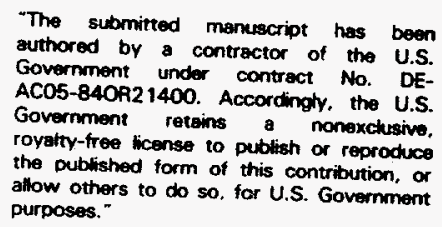




\section{DISCLAIMER}

Portions of this document may be illegible in electronic image products. Images are produced from the best available original document. 
Tensile stress relaxation testing is more difficult for ceramics than for metals for two reasons. Firstly, maintaining a constant strain requires a very stable extensometer signal because the significantly higher elastic modulus of ceramics will result in large stress fluctuations for even slight fluctuations in strain. Secondly, being that ceramics are more refractory than metals, creep-induced stress relaxation behavior is activated at much higher temperatures. Therefore, the furnace temperature must be very stable because temperature variation can cause thermal expansion or contraction that will affect the strain. Thus, test hardware must simultaneously maintain a strain and high temperatures with small fluctuations.

Descriptions of using stress relaxation testing to predict long-term creep rate as a function of stress exist in the literature [1-2]. The method has been examined by several investigators to predict long-term creep rate - stress effects (i.e., where the creep rate is less than $10^{-9} / \mathrm{s}$ ) in various structural ceramics [35]. Caution must be exercised though when interpreting data generated from stress relaxation because the relaxation behavior will be different depending on the total amount of strain (i.e., how much permanent, accumulated damage) that was held constant during the test.

The present study utilizes this test technique to compare the tensile stress relaxation behavior of SN88, SN253, and NCX-5102 silicon nitride materials tested at the same temperature $\left(1300^{\circ} \mathrm{C}\right)$ and the same initial tensile stresses $(276$ or $414 \mathrm{MPa}$ ). The relaxed tensile stress as a function of time is described using the generalized Maxwell model with a special, non-negative least squares algorithm that yields a relaxation spectrum that is characteristic of the stress decay history. Lastly, creep exponents for the three silicon nitrides are determined from reduced stress relaxation data and compared with creep exponents determined from tensile creep tests conducted at similar test conditions.

\section{EXPERIMENTAL PROCEDURES}

The stress-relaxation behaviors of SN88, ${ }^{\dagger} \mathrm{SN} 253$, ${ }^{\dagger \dagger}$ and NCX-5102 silicon nitrides were examined in this study. SN88 and SN253 were densified by gas-pressure sintering. Although the sintering aids and their amounts were not supplied by the SN88 and SN253 vendors, EDAX showed that both contained aluminum and ytterbium in their grain boundaries. NCX-5102 is hotisostatically pressed and was densified with $4 \%$ yttria as a sintering aid. The as-received microstructures of all three silicon nitrides were similar in that acicular-shaped grains were mixed with smaller equiaxed grains.

The accuracy of the testing machine's load cell, strain-control capability, specimen alignment, in addition to the specimen geometry and temperature control, satisfied ASTM E328-86 for stress relaxation testing [6]. The buttonhead specimen geometry was employed in the present study, with specimen gage section dimensions consisting of a $6.35 \mathrm{~mm}$ (SN253 and SN88) or

\footnotetext{
$\dagger \quad$ NGK Insulators, LTD., Nagoya, Japan.

t† Kyocera Corp., Kagoshima, Japan.

itt Saint-Gobain / Norton Industrial Ceramics Corp., Northboro, MA.
} 
$6.0 \mathrm{~mm}$ (NCX-5102) diameter and a $35 \mathrm{~mm}$ gage length. A short, two-zone furnace mounted on an electromechanical testing machine provided a $50 \mathrm{~mm}$ hot zone to heat the specimen's gage section, while the specimen's ends were cold gripped outside the furnace. Testing was conducted at $1300^{\circ} \mathrm{C}\left(2370^{\circ} \mathrm{F}\right)$, and the variability of the temperature was less than $\pm 5 \mathrm{C}^{\circ}$. The test machine was equipped with analog, PID $\$$-adjustable load and strain controllers. Strain was monitored using a high-temperature contact extensometer, and its signal conditioner provided electronic, closed-loop feedback. Stress relaxation testing involved loading the specimen at $10 \mathrm{MPa} / \mathrm{s}$ to a predetermined stress (276 $\mathrm{MPa}$ (40 ksi) or $414 \mathrm{MPa}(60 \mathrm{ksi})$ ) in load control, then changing to strain control to maintain a constant strain; as a consequence, stress decayed as a function of time. Remaining tensile stress, extensometer output, and temperature were monitored as a function of time using a personal computer throughout the duration of the test.

\section{RESULTS \& DISCUSSION \\ IIIA. STRESS RELAXATION RESULTS}

The stress relaxation histories (remaining tensile stress as a function of time) for the three examined silicon nitrides are shown in Figs. 1 (a) and (b) for $\sigma_{0}=276 \mathrm{MPa}$ and $\sigma_{0}=414 \mathrm{MPa}$, respectively. Tests were terminated after it was estimated that the stress decay rate had become minimal. For both initial stresses, the SN88 relaxed the most for a given amount of time, followed by SN253 and NCX-5102. For silicon nitride components that are mechanically fastened (e.g., a component that has a shrink fitted arbor on a shaft) at $1300^{\circ} \mathrm{C}$, these data show that NCX-5102 will be able to maintain the greatest amount of clamping stress because it relaxes the least. However, components made from NCX-5102 may not be able to sufficiently relax potentially debilitating stressconcentrators as well as SN88 or SN253.

\section{IIB. REPRESENTING STRESS RELAXATION BEHAVIOR}

The generalized Maxwell model was chosen in the present study because it effectively represents stress relaxation behavior [7]. A schematic illustration of this is shown in Fig. 2. The spring in each Maxwell model represents its elastic contribution, while the dashpot describes the viscous contribution; the two acting in concert describe a characteristic relaxation time constant, $\tau_{\mathrm{i}}$, that is numerically equal to $\eta_{i} / E_{i}$. For the stress relaxation tests, the tensile specimens were loaded to an initial stress, $\sigma_{0}$, and then its corresponding strain, $\varepsilon_{0}$, was held constant. All the parallel models shown in Fig. 2 are subjected to this strain; stress will subsequently decay as a function of time because the dashpots in each model deform and lessen the stress.

For a discrete number $(\mathrm{N})$ of Maxwell models in parallel, the remaining stress as a function of time during stress relaxation, $\sigma(t)$, is represented by [7]:

$$
\sigma(t)=\varepsilon_{0} \sum_{i=1}^{\mathbb{N}} E_{i} \exp \left(\frac{-t}{\tau_{i}}\right)
$$

$\S \quad$ Proportional loop gain - integral - derivative 
where $\varepsilon_{0}$ is the magnitude of the constant strain, $E_{\mathrm{i}}$ is the relaxation modulus of the $\mathrm{i}$-th Maxwell model, and $\tau_{\mathrm{i}}=\eta_{\mathrm{i}} / \mathrm{E}_{\mathrm{i}}$ is the relaxation time constant (where $\eta_{\mathrm{i}}$ is the viscosity of the dashpot of the $\mathrm{i}$-th Maxwell model). The stress relaxation data were regressed against Eq. 1 to create a relaxation spectrum, $E(\tau)$ versus $\tau$ [8-9]. Restrictions were placed on the analysis to ensure that positive values of $\mathrm{E}_{\mathrm{i}}$ were yielded as negative moduli have no physical meaning.\$

Relaxation moduli spectra were determined for six specimens ( 2 of each material). An example of such a spectrum is illustrated in Fig. 3a with its associated prediction of $\sigma(\mathrm{t})$ represented by the solid line in Fig. 3b. The relaxation moduli and the corresponding relaxation time constants are listed in Table 1 for all six specimens. Note that in Table 1 each specimen has one relaxation time constant equal to infinity; this represents one Maxwell model that has a dashpot with an infinite viscosity signifying that it does not relax; it is necessary to explain the remnant stress (e.g., the $\approx 60-70 \mathrm{MPa}$ of unrecovered stress in Fig. $3 b$ ). $\tau_{\mathrm{i}}=\infty$ (or $\eta_{i}=\infty$ ) and its corresponding relaxation modulus are not shown in Fig. 3a. In addition, the sum of all the relaxation moduli for any given specimen represents that specimen's elastic modulus (see Table 1). The relaxation moduli, relaxation time constants, and even the number of discrete elements are a "fingerprint" of the stress relaxation history for the given test duration. Thus, the stress decay of components made from any of these three materials may be described using the determined values of $E_{\mathbf{i}}$ and $\tau_{i}$, provided the initial stress, hold strain, temperature, and duration are the same. Efforts are underway to examine how the spectra may be predicted as a function of applied initial stress and temperature.

\section{IIIC. CREEP RATE AS A FUNCTION OF TENSILE STRESS}

Stress relaxation testing may be used to survey several decades of creep rates and corresponding stresses in a test duration that lasts only hours or days; whereas, the alternative static creep testing may take hundreds or even thousands of hours to generate equivalent data. For this approach, the total creep strain $\left(\varepsilon_{t}\right)$ is represented by the sum of elastic strain $\left(\varepsilon_{\mathrm{e}}\right)$ and inelastic $\left(\varepsilon_{\mathrm{in}}\right)$ strain, where $\varepsilon_{\text {in }}$ is the sum of anelastic $\left(\varepsilon_{\mathrm{a}}\right)$, and plastic strain $\left(\varepsilon_{\mathrm{p}}\right)$. When the total creep strain is held constant in a stress relaxation test, the following may be considered:

$$
\dot{\varepsilon_{\text {in }}}=-\dot{\varepsilon_{\mathrm{e}}}=-\frac{1}{\mathrm{E}} \dot{\sigma}
$$

where the dots denote time derivatives, and the last term relates the elastic stressing rate with the elastic straining rate. $\dot{\sigma}$ was experimentally determined and the inelastic strain rate was calculated using Eq. 2. The relationship of the creep rate as a function of stress is shown for the three silicon nitrides tested with $\sigma_{0}=276 \mathrm{MPa}$ and $414 \mathrm{MPa}$, Figs. 4 (a) and (b), respectively. Power-

\$ For discription of method, see section on non-negative least squares in Solving Least Squares Problems, C. L. Lawson and R. J. Johnson, Prentice-Hall, Englewood Cliffs, NJ, 1974. 
law curve fitting was performed and the values of the creep exponents, $n$, are shown in the legends. Within statistical error, the creep exponents were equivalent for specimens tested with $\sigma_{0}=276 \mathrm{MPa}$ and $414 \mathrm{MPa}$. The determined creep exponents were 6, 5, and 4, for NCX-5102, SN253, and SN88, respectively. Although creep exponents generated from tensile creep at $1300^{\circ} \mathrm{C}$ for the three silicon nitride materials are unknown, a creep exponent for NCX -5102 at $1370^{\circ} \mathrm{C}$ of 6 has been determined [10] and preliminary creep exponents of 6 and 8 have been determined at $1288^{\circ} \mathrm{C}$ for SN 253 and SN88, respectively [11]. The creep exponents generated by the two techniques are comparable for the NCX-5102 and SN253, but are quite different for the SN88.

Further scrutiny and interpretation of the stress exponents generated from the stress relaxation testing are continuing and are being reconciled with the stress exponents generated from the static creep tests. Note that caution must be exercised when comparing stress or creep exponents generated from static creep and stress relaxation tests; stress exponent values from static creep tests are determined from the minimum or steady-state creep rate, while the stress exponent generated from stress relaxation testing may differ depending on the total strain held constant during the relaxation test. The relaxation behavior may be different for low or primary-creep regime strains than for higher or secondary-creep regime strains.

\section{CONCLUSIONS}

The tensile stress relaxation behavior of NCX-5102, SN88, and SN253 was examined under conditions of $1300^{\circ} \mathrm{C}$ with initially applied stresses of $276 \mathrm{MPa}(40 \mathrm{ksi})$ and $414 \mathrm{MPa}(60 \mathrm{ksi})$. For any given time after commencement of the stress relaxation, NCX-5102 relaxed the least, followed by SN253 and SN88. This suggests that components made from NCX-5102 would maintain higher clamping stress or torque at $1300^{\circ} \mathrm{C}$ than $\mathrm{SN} 253$ or SN88 if they were mechanically fastened or joined. However, an alternative perspective would argue that SN88 would more efficiently relax the stress around a potentially detrimental stress concentrator than SN253 or NCX-5102. How the stress relaxation behavior of these three materials is utilized depends on whether the designer requires the maintenance of stress or the rapid stress relaxation around a stress concentrator.

A generalized Maxwell model in conjunction with the described nonnegative least squares analysis proved to be an efficient means to describe the history of stress relaxation. The analysis yields a relaxation moduli spectrum, $\mathrm{E}(\tau)$ vs. $\tau$, that has a physical basis.

The creep exponents of NCX-5102, SN253, and SN88 at $1300^{\circ} \mathrm{C}$ were generated from analysis of stress relaxation data and determined to be approximately 6,5 , and 4 , respectively. These creep exponents were determined at low strains where there probably was not a significant amount of permanent damage. Creep rates as low as $10^{-10} / \mathrm{s}$ were achieved via testing that lasted only days. 


\section{ACKNOWLEDGMENTS}

The authors wish to thank Drs. J. R. Keiser and T. R. Watkins for reviewing the manuscript and for their helpful comments.

\section{REFERENCES}

[1] J. Lamaitre and J. -L. Chaboche, Mechanics of Solid Materials, Cambridge University Press, Cambridge, UK, 1994.

[2] D. A. Woodford, "Test Methods for Accelerated Development, Design, and Life Assessment of High Temperature Materials," Materials and Design, 14 [4] 231-42 (1993).

[3] A. A. Wereszczak, T. P. Kirkland, M. K. Ferber, "Stress and Strain Relaxation Behaviour in HIPed Silicon Nitrides," J. Mat. Sci. Lett., 13 1469-71 (1994).

[4] D. A. Woodford, D. R. VanSteele, and M. J. Hyder, "Tensile Stress Relaxation of Alumina at High Temperature," J. Am. Ceram. Soc., 74 [12] 3142-44 (1991).

[5] M. G. Jenkins and M. K. Ferber, "Stress-Relaxation Tests Used to Determine the Elevated-Temperature Creep Parameters of Structural Ceramics," Fracture Mechanics of Ceramics, Vol. 10, pp 539-53, Eds. R. C. Bradt, D. P. H. Hasselman, D. Munz, M. Sakai, and V. Ya. Shevchenko, Plenum Press, New York, 1992.

[6] "Standard Methods for Stress Relaxation Tests for Materials and Structures," ASTM E 328-86, Vol. 03.01, Metals Test Methods and Analytical Procedures, 1990 Annual Book of ASTM Standards, ASTM, Philadelphia, PA, 1990.

[7] W. N. Findley, J. S. Lai, and K. Onaran, Creep and Relaxation Behavior of Nonlinear Viscoelastic Materials, Dover Publications, Inc. New York, 1989.

[8] L. Thigpen, G. W. Hedstrom, and B. P. Bonner, "Inversion of Creep Response for Retardation Spectra and Dynamic Viscoelastic Functions," J. Appl. Mech., 50 361-66 (1983).

[9] T. T. Gribb, S. Zhang, and R. F. Cooper, "Melt Migration and Related Attenuation in Equilibrated Partial Melts," Magmatic Systems, pp 19-36, Edt. M. P. Ryan, Academic Press, Inc. New York, 1994.

[10] A. A. Wereszczak, T. P. Kirkland, and M. K. Ferber, "Differences in Creep Performance of a HIPed Silicon Nitride in Ambient Air and Inert Environments," Cer. Engrg. Sci. Proc., 1995.

[11] M. K. Ferber and A. A. Wereszczak, unpublished data, 1994.

\section{DISCLAIMER}

This report was prepared as an account of work sponsored by an agency of the United States Government. Neither the United States Government nor any agency thereof, nor any of their employees, makes any warranty, express or implied, or assumes any legal liability or responsibility for the accuracy, completeness, or usefulness of any information, apparatus, product, or process disclosed, or represents that its use would not infringe privately owned rights. Reference herein to any specific commercial product, process, or service by trade name, trademark, ence herein to any specific constite or imply its endorsement, recommendation, or favoring by the United States Government or any agency thereof. The views and opinions of authors expressed herein do not necessarily state or reflect those of the United States Government or any agency thereof. 
Table. 1. Determined relaxation moduli and relaxation time constants.

\begin{tabular}{|c|c|c|c|c|}
\hline Material & $\begin{array}{c}\sigma_{0} \\
(\mathrm{MPa})\end{array}$ & $\mathrm{N}$ & $\begin{array}{c}\tau_{\mathrm{i}} \\
(\mathrm{s})\end{array}$ & $\begin{array}{c}\mathrm{E}_{\mathrm{i}} \\
(\mathrm{GPa})\end{array}$ \\
\hline \multirow[t]{5}{*}{ NCX-5102 } & 276 & 4 & $\tau_{1}=306$ & $E_{1}=14.3$ \\
\hline & & & $\tau_{2}=2893$ & $\mathrm{E}_{2}=88.7$ \\
\hline & & & $\tau_{3}=21818$ & $E_{3}=77.5$ \\
\hline & & & $\tau 4=\infty$ & $E_{4}=144.2$ \\
\hline & & & & $E_{\text {tot }}=325$ \\
\hline \multirow[t]{6}{*}{ NCX -5102} & 414 & 5 & $\tau_{1}=312$ & $E_{1}=27.6$ \\
\hline & & & $\tau_{2}=3110$ & $E_{2}=108.8$ \\
\hline & & & $\tau_{3}=14390$ & $\mathrm{E}_{3}=33.1$ \\
\hline & & & $\tau_{4}=110944$ & $E_{4}=47.7$ \\
\hline & & & $\tau 5=\infty$ & $E_{5}=68.3$ \\
\hline & & & & $E_{t o t}=286$ \\
\hline \multirow[t]{5}{*}{ SN88 } & 276 & 4 & $\tau_{1}=340$ & $E_{1}=25.9$ \\
\hline & & & $\tau_{2}=2898$ & $E_{2}=66.3$ \\
\hline & & & $\tau_{3}=31302$ & $E_{3}=77.0$ \\
\hline & & & $\tau_{4}=\infty$ & $E_{4}=46.4$ \\
\hline & & & & $E_{t o t}=216$ \\
\hline \multirow[t]{5}{*}{ SN88 } & 414 & 4 & $\tau_{1}=145$ & $\mathrm{E}_{1}=22.2$ \\
\hline & & & $\tau_{2}=1441$ & $E_{2}=72.4$ \\
\hline & & & $\tau_{3}=66248$ & $E_{3}=80.5$ \\
\hline & & & $\tau_{4}=\infty$ & $E_{4}=28.8$ \\
\hline & & & & $E_{\text {tot }}=204$ \\
\hline \multirow[t]{5}{*}{ SN253 } & 276 & 4 & $\tau_{1}=321$ & $\mathrm{E}_{1}=24.5$ \\
\hline & & & $\tau_{2}=3080$ & $E_{2}=44.2$ \\
\hline & & & $\tau_{3}=23620$ & $E_{3}=107.3$ \\
\hline & & & $\tau_{4}=\infty$ & $E_{4}=100.0$ \\
\hline & & & & $E_{\text {tot }}=276$ \\
\hline \multirow[t]{7}{*}{ SN253 } & 414 & 6 & $\tau_{1}=338$ & $E_{1}=61.6$ \\
\hline & & & $\tau_{2}=952$ & $E_{2}=3.8$ \\
\hline & & & $\tau_{3}=3473$ & $E_{3}=79.7$ \\
\hline & & & $\tau_{4}=21257$ & $E_{4}=41.3$ \\
\hline & & & $\tau_{5}=130114$ & $E_{5}=45.8$ \\
\hline & & & $\tau_{6}=\infty$ & $E_{6}=45.7$ \\
\hline & & & & $E_{\text {tot }}=278$ \\
\hline
\end{tabular}



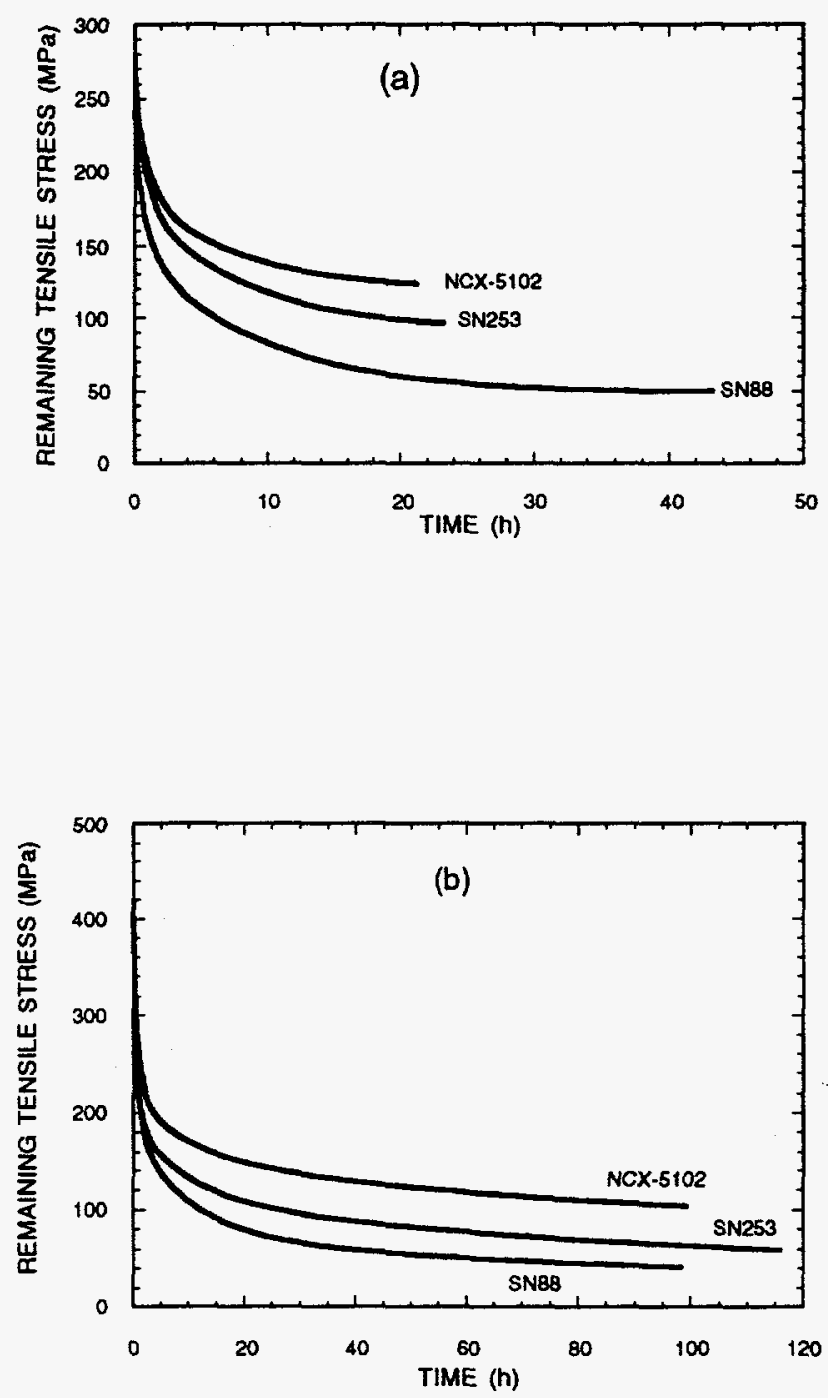

Fig. 1. Stress relaxation histories of NCX-5102, SN88, and SN253 tested at $1300^{\circ} \mathrm{C}$ with an initially applied stress of (a) $276 \mathrm{MPa}$ or $40 \mathrm{ksi}$, and (b) $414 \mathrm{MPa}$ or $60 \mathrm{ksi}$. 


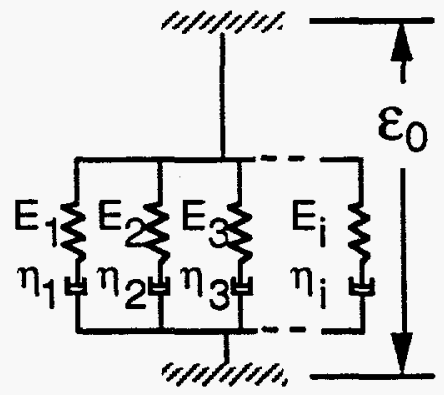

Fig. 2. Maxwell models in parallel were used to represent stress decay as a function of time, $\sigma(t)$, for a known constant strain, $\varepsilon_{0}$.
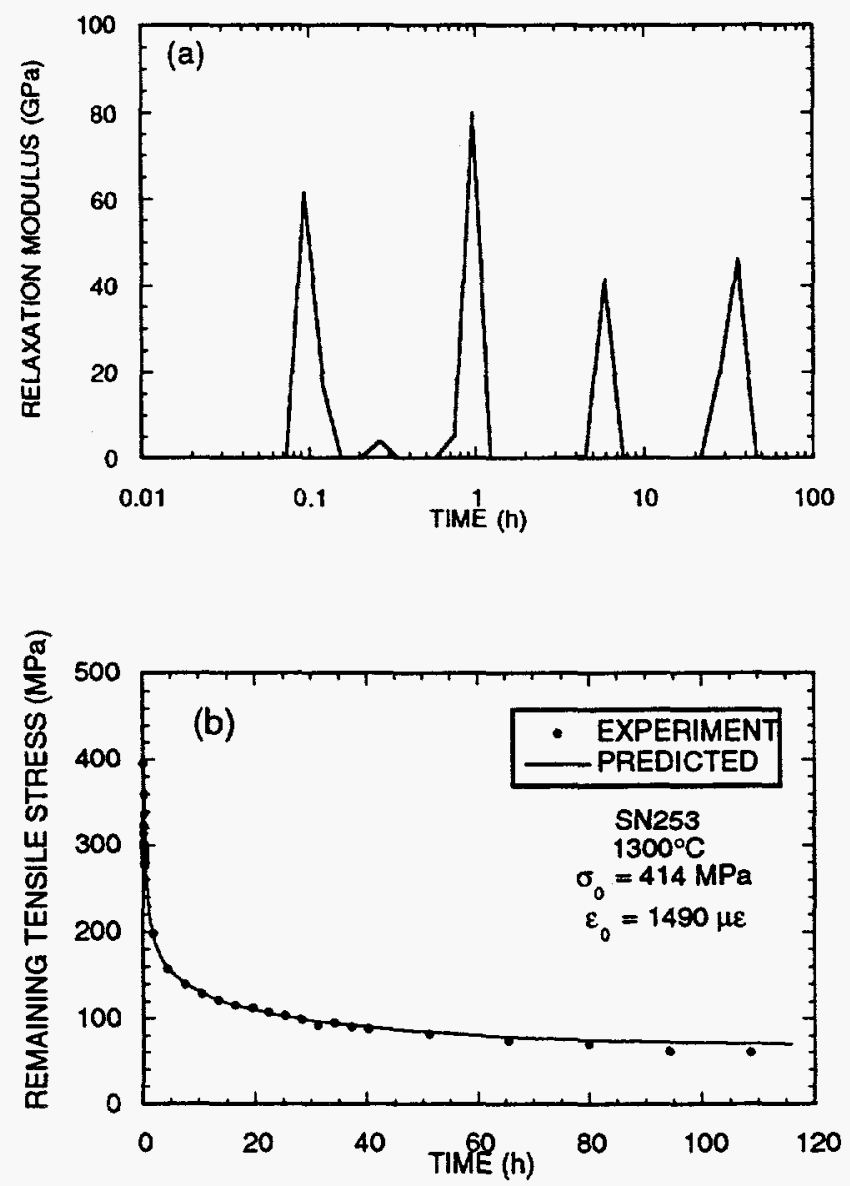

Fig. 3. Example of (a) determined discrete relaxation moduli and their corresponding relaxation times, and (b) the stress decay history that their values predict. Example shown is SN253 silicon nitride with $\sigma_{0}=414 \mathrm{MPa}$ and $\varepsilon_{0}=1490 \mu \varepsilon$. 

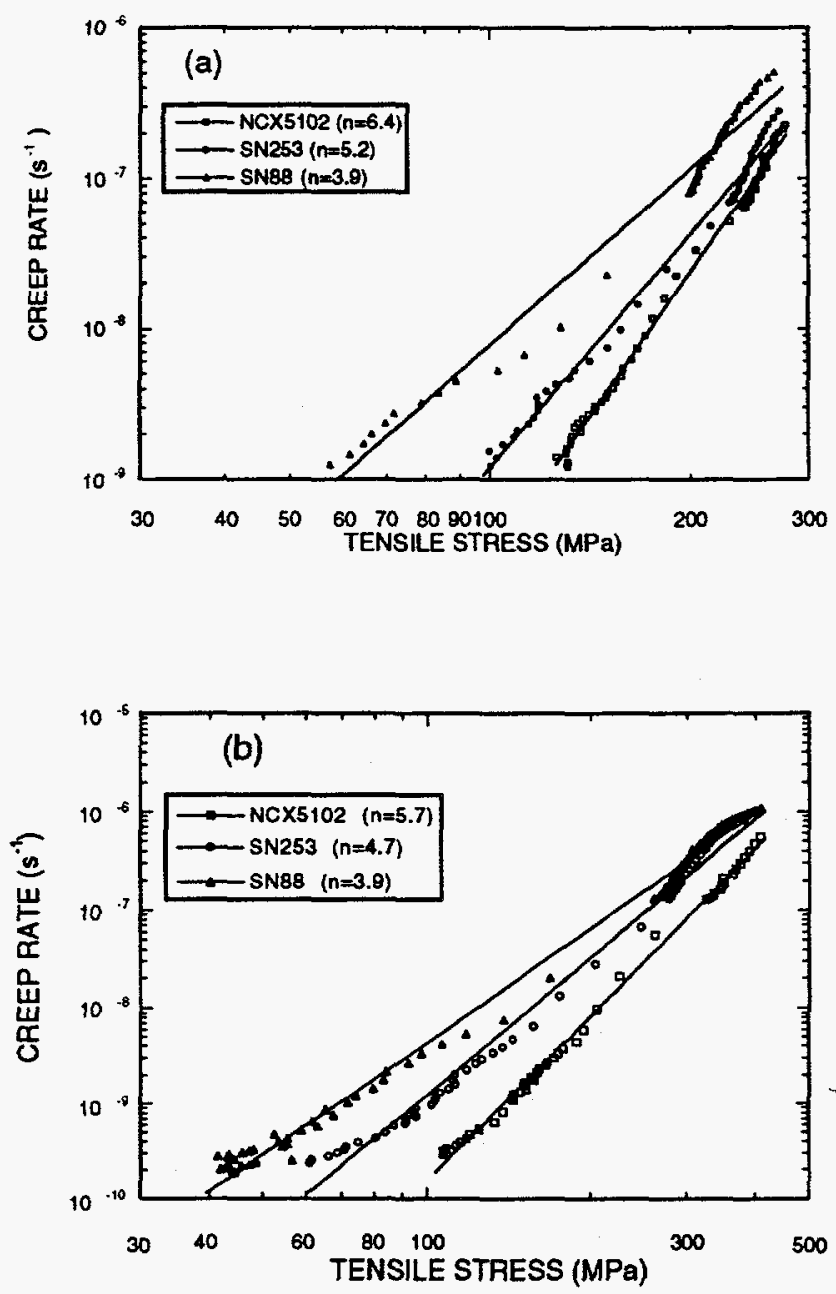

Fig. 4. Creep rate as a function of tensile stress determined using Eq. 2 and from stress relaxation tests conducted with (a) $\sigma_{0}=276 \mathrm{MPa}$, and (b) $\sigma_{0}=414 \mathrm{MPa}$. Values shown in the legends are power-law fitted creep exponents. 